\title{
Opening Note: Jean-Louis Koszul in São Paulo, his work and legacy
}

\section{Claudio Gorodski ${ }^{1}$}

Published online: 21 October 2021

(c) Instituto de Matemática e Estatística da Universidade de São Paulo 2021

Claude Lévi-Strauss had taught at the humanities section of the University of São Paulo (USP) in 1935-1938. In 1944, he introduced André Weil to the geneticist and Dean of Sciences at USP, André Dreyfus, who was then on a research trip to the United States. USP, only recently founded, had at first chosen French scholars to teach disciplines in the humanities, and Italians for the sciences. Because war had been declared between Brazil and Italy, the Italian professors (Luigi Fantappiè and Giacomo Albanese) had been obliged to repatriate; there was thus a chair in mathematics that needed to be filled. As recounted in his book, Souvenirs d'apprentissage, Weil was in a rather precarious situation in the U.S. and gladly took the offer to work at USP. He arrived with his family in São Paulo in January 1945 and had a pleasant stay. With the allied liberation of Paris, in 1944, the activities of the Bourbaki group, which included Weil, had resumed. His friend, Oscar Zariski, was also visiting São Paulo in 1945, and Jean Dieudonné spent the years 1946 and 1947 there. However, eventually it was impossible for Weil not to wish for a more stimulating scientific milieu, and he left for Chicago by the end of 1947. Jean Delsarte, another bourbakist, visited USP several times in the years 1948-1951. In 1952, there were visits by Laurent Schwartz, Dieudonné again, Charles Ehresmann and Samuel Eilenberg. Also, Alexander Grothendieck was a professor at USP in 1953-1954, where he published his celebrated lecture notes about topological vector spaces. The influence of Bourbaki on Mathematics at USP cannot be overestimated. They advised students and introduced several conjuntistic, topological and algebraic structures in the curricula, helping to forge the modern viewpoint. According to Michel Ngiffo Boyom, retired professor at Montpellier, it is said that Bourbaki had two subsidiaries in the world: one was located in Mumbai and the other in São Paulo.

Jean-Louis Koszul was born in Strasbourg in 1921. He entered L'École Normale Supérieure de Paris in 1940, and defended his Ph.D. Thesis about homology and

Claudio Gorodski

gorodski@ime.usp.br

1 University of São Paulo, São Paulo, Brazil 
cohomology of Lie algebras under the supervision of Henri Cartan in 1949. He then became maitre de conférences at the University of Strasbourg, and was promoted to professor in 1956. Koszul eventually became a member of the second generation of Bourbaki, together with J. Dixmier, R. Godement, S. Eilenberg, P. Samuel, J.-P. Serre and L. Schwartz. His visits to Brazil were co-organized by USP and IMPA (created in 1952). The first visit happened in 1956, when he taught courses on multilinear algebra, sheaf cohomology and Kähler manifolds in São Paulo. The three sets of lecture notes were published there, namely, Álgebra multilinear (in Portuguese, translated by L. H. Jacy Monteiro, published in 1956), Faisceaux et cohomologie (in French, 1957) and Variétés Kählériennes (in French, 1957).

To put in perspective Koszul's second visit to USP in 1958, we mention that, according to Pierre Cartier, André Weil had assigned to Koszul the task of recovering the legacy of Élie Cartan about the Riemannian symmetric spaces and the bounded homogeneous domains for the Bourbaki group. In September and October of 1958, Koszul taught a course on symmetric spaces at USP, whose lecture notes Exposés sur les espaces homogènes symétriques were published in the following year. According to R. Bott in Math Reviews: "These are notes on symmetric spaces from a seminar conducted by the author in São Paulo during the fall of 1958. The notes are meant for readers who know the rudiments of geometry and the theory of Lie groups, and are very enjoyable. The pace is quick, and considerable material is covered elegantly. Apart from the more or less standard theorems on symmetric spaces, the author discusses the geometry of geodesics, the Bergmann metric, and finally investigates the bounded domains in considerable detail."

Koszul became professor at the University of Grenoble in 1963, and hosted A. A. Martins Rodrigues, professor of differential geometry at USP, in Grenoble during 1967-1970, when they discussed Lie pseudogroups. He was elected to Academia de Ciências do Estado de São Paulo in 1981, and visited USP one last time in 1986, hosted by Rodrigues, in order to give one inaugural talk at the Instituto de Estudos Avançados, with title: "The genesis of Bourbaki".

This issue of SPJM contains a short number of works from participants in the Second Workshop of the São Paulo Journal of Mathematical Sciences: Jean-Louis Koszul in São Paulo, His Work and Legacy, held at USP in 13-14 November 2019 (https://www.ime.usp.br/ 2wspjm/), ${ }^{1}$ in various subjects related to his fields of interest. We hope that readers will appreciate the choice of topics.

Publisher's Note Springer Nature remains neutral with regard to jurisdictional claims in published maps and institutional affiliations.

\footnotetext{
${ }^{1}$ We acknowledge generous financial support from Fapesp (Grants No. 2019/05955-5 and 2016/23746$6)$. 